\begin{tabular}{|c|c|c|c|}
\hline \multirow{3}{*}{$\begin{array}{r}\text { Case Reports in } \\
\text { Gastroenterology }\end{array}$} & \multirow{2}{*}{\multicolumn{2}{|c|}{ Case Rep Gastroenterol 2018;12:32-40 }} & \multirow[b]{3}{*}{ Oparger } \\
\hline & & & \\
\hline & $\begin{array}{l}\text { DOI: } 10.1159 / 000486390 \\
\text { Publisned online: January 19, } 2018\end{array}$ & $\begin{array}{l}\text { (C) } 2018 \text { The Author(s) } \\
\text { Published by S. Karger AG, Basel } \\
\text { www.karger.com/crg }\end{array}$ & \\
\hline & $\begin{array}{l}\text { This article is licensed under the } \\
\text { International License (CC BY-NC) } \\
\text { Usage and distribution for commerc }\end{array}$ & $\begin{array}{l}\text { mons Attribution-NonCommercial } 4.0 \\
\text { rger.com/Services/OpenAccessLicense). } \\
\text { quires written permission. }\end{array}$ & \\
\hline
\end{tabular}

\title{
Endoscopic versus Laparoscopic Full- Thickness Biopsy in the Pathological Evaluation of the Enteric Nervous System
}

\author{
Bodil Ohlsson $^{a} \quad$ Rita J. Gustafsson ${ }^{b}$ Ervin Toth ${ }^{b}$ Bèla Veress ${ }^{c}$ \\ Henrik Thorlacius ${ }^{d}$ \\ ${ }^{a}$ Department of Internal Medicine, Skåne University Hospital, Lund University, \\ Malmö, Sweden; ${ }^{b}$ Department of Gastroenterology, Skåne University Hospital, Lund \\ University, Malmö, Sweden; 'Department of Pathology and Molecular Biology, Unilabs AB, \\ Skövde, Sweden; ${ }^{d}$ Department of Surgery, Skåne University Hospital, Lund University, \\ Malmö, Sweden
}

\section{Keywords}

Enteric neuropathy · Enteric dysmotility · Full-thickness biopsy · Gastrointestinal symptoms

\begin{abstract}
A full-thickness biopsy of the bowel wall is required to evaluate the enteric nervous system. A patient with aggravating gastrointestinal symptoms underwent a laparoscopic full-thickness biopsy of the ileum and, 1 year later, an endoscopic full-thickness biopsy of the sigmoid colon. Both samples showed enteric neuropathy characterized by vacuolated and enlarged neurons. The length of the myenteric plexus was greater in the endoscopic $(23 \mathrm{~mm}) \mathrm{com}-$ pared to the laparoscopic $(11 \mathrm{~mm})$ biopsy, with fewer tissue artefacts in the laparoscopic approach. Clinical deterioration was paralleled by enteric neuropathy with an increase in the percentage of vacuolated and enlarged enteric neurons from 24 to $35 \%$.
\end{abstract}

(C) 2018 The Author(s)

Published by S. Karger AG, Basel 


\section{Introduction}

Enteric dysmotility and chronic intestinal pseudo-obstruction are conditions affecting the enteric nervous system (ENS) and/or the intestinal muscle layers with clinical characteristics of severe abdominal pain and dysmotility [1]. The diagnoses are set after careful clinical examination combined with examinations of gastrointestinal motility [1]. ENS is part of the autonomic nervous system, and a full-thickness bowel biopsy is needed to characterize its histopathology [2]. The sampling procedure demands a laparoscopy performed with full anesthesia $[3,4]$. Due to the complicated procedure, knowledge about the pathogenesis of the diseases is limited. Recently, an endoscopic device has been developed to obtain fullthickness biopsies from the bowel wall without laparotomy and anesthesia [5]. This is a promising minimally invasive procurement of intestinal full-thickness biopsies for the diagnosis of intestinal neuropathies and myopathies, which could be an advance in the research field of these diseases.

Gonadotropin-releasing hormone $(\mathrm{GnRH})$ analogs are used in the treatment of endometriosis to downregulate secretion of gonadotropins and sex hormones [6]. Nausea and abdominal pain are reported side effects in treated patients [7]. Besides in the brain and gonads [6], GnRH1, GnRH2, and receptors for luteinizing hormone (LH) are expressed in enteric neurons $[4,8-10]$. We have previously reported how some women have developed severe dysmotility and GnRH antibodies after treatment with GnRH analogs $[4,11]$.

The primary aim of the present report was to describe and compare the quality of fullthickness biopsies from the gastrointestinal tract in endoscopic and laparoscopic biopsy samplings of a woman with enteric dysmotility secondary to GnRH treatment. The secondary aim was to examine whether there was a progression over time in the histopathological characteristics.

\section{Materials and Methods}

\section{Clinical Anamnesis and Examination}

The patient had suffered from sporadic abdominal complaints during her childhood. These complaints worsened after menarche, and she was diagnosed with endometriosis at 20 years of age. She received a single therapy period with the GnRH analog nafarelin for endometriosis. The recommended treatment period of at least 6 months was completed, but the exact duration of the treatment period is uncertain. During this treatment, the abdominal complaints were aggravated with pain, bloating, and nausea, the complaints being more pronounced the longer the treatment lasted. In addition, profound sweating was present. A chronic progress of gastrointestinal symptoms continued, also after treatment cessation.

A clinical workup was started at the Department of Gastroenterology when she was 24 years of age. Colonoscopy and capsule enteroscopy did not reveal any mucosa lesions. Oroanal transit time was 1.8 days. Computer tomography, magnetic resonance tomography, and ultrasound did not reveal any pathology in the kidneys, liver, or gallbladder, but signs of delayed gastric emptying rate were apparent. A tilt-table test revealed postural orthostatic tachycardia syndrome, and long-term registration of electrocardiography revealed sinus tachycardia. Neurological and rheumatological diseases were excluded. Antibodies against the acetylcholine receptor or JC virus could not be detected in the serum. 
Ohlsson et al.: Endoscopic versus Laparoscopic Full-Thickness Biopsy in the Pathological Evaluation of the Enteric Nervous System

\section{Molecular Biological Examination}

DNA was extracted from whole blood and polymerase chain-reaction was used to amplify the GnRH receptor (GnRHR) gene's 3 exons and LH/choriogonadotropin receptor (LHCGR) gene's 11 exons. The patient was a heterozygous carrier of the rare G allele at the SNP rs6755901 of the LH receptor gene, which is usually present at minor allele frequency of 0.15 in the general Caucasian (CEU) population [11]. IgM antibodies against progonadoliberin-2 and GnRH, but not against GnRH receptor, $\mathrm{LH}$, or LH receptor, were visualized in the serum by ELISA [11-13].

\section{Full-Thickness Biopsy Sampling of the Bowel}

A previously described laparoscopy-assisted technique was initially performed for diagnostic purposes to obtain a full-thickness biopsy of the ileum [3, 4]. One year later, an endoscopic full-thickness biopsy was obtained of the sigmoid colon through endoscopic fullthickness resection (Ovesco, Tübingen, Germany) [14]. The same technique has been used in a pig model to obtain a full-thickness biopsy for neuromuscular diagnosis, which showed that the examination was positive and the quality of the sample biopsy was good [5]. Briefly, a full-thickness specimen was obtained followed by endoscopic closure of the bowel wall defect $[5,14]$.

\section{Histopathology and Immunohistochemistry}

The same preparation of biopsies was used as that previously described for laparoscopic biopsies [3, 4]. Briefly, the biopsies were fixed in $4 \%$ formalin before three full-thickness slices were cut out and embedded in paraffin. Sections with a thickness of 3-4 $\mu \mathrm{m}$ were stained with hematoxylin \& eosin (H\&E), periodic acid-Schiff (PAS), PAS diastase, Giemsa, and trichrome. The following immunohistochemical staining was applied for specific analysis of neurons (human neuronal protein [HuC/D], synaptophysin, vimentin, Bcl-2, and p62), glial and Schwann cells (S100), T lymphocytes (CD3), intermediate/microfilaments of the smooth muscle cells ( $\alpha$-actin, desmin), and the interstitial cells of Cajal (CD117) [3, 4]. The histopathological findings were classified as defined earlier [1]. The criteria for the neuropathies and myopathies were based upon criteria suggested by the Gastro 2009 International Working Group for Gastrointestinal Neuromuscular Pathology [15]. For quantitative analysis, both myenteric cells with normal cytomorphology and those with vacuolated degeneration were counted in H\&E-stained sections. Sections from 4 normal small intestinal tissue samples of bowel resection due to intestinal carcinomas served as reference samples for immunohistochemical staining [4].

\section{Results}

\section{Clinical Findings}

At the time point of the initial laparoscopic biopsy, the patient suffered from severe abdominal pain, visible severe bloating with tympanism, and constipation. She needed oral nutritional support, since the abdominal pain reduced her food intake and she lost weight (5 kg; $6 \%$ of body weight) and exhibited low values of serum albumin (fluctuating around $30 \mathrm{~g} / \mathrm{L}$; reference value: $36-48 \mathrm{~g} / \mathrm{L}$ ) and blood hemoglobin (fluctuating around $110 \mathrm{~g} / \mathrm{L}$; reference value: $117-153 \mathrm{~g} / \mathrm{L}$ ). The pain was that severe that she needed a walker to move between the bed and the toilet. She used several laxatives and prokinetic agents and, due to 
the pain, consumed opioid analgesics and antidepressant drugs. Inspection of the abdominal cavity at the laparoscopy could not reveal any persistent signs of endometriosis.

One year after the initial full-thickness biopsy, the abdominal pain and bloating was still present and increasingly worse. The patient had been hospitalized 1-3 times/month (for 2-10 days each time) for parenteral nutritional support, and had become more or less dependent on opioid analgesics. The values were even lower than previously for serum albumin (fluctuating around $20 \mathrm{~g} / \mathrm{L}$ ) and blood hemoglobin (fluctuating around $90 \mathrm{~g} / \mathrm{L}$ ), but the body weight was regained.

\section{Histopathological Findings}

No histopathological changes were seen in the mucosa, submucosa, muscle layers, interstitial cells of Cajal, or submucosal neural plexus in the bowel biopsies, in comparison to reference samples [4].

The whole length of the myenteric plexus was $11.0 \mathrm{~mm}$ in the laparoscopic biopsy and $23.2 \mathrm{~mm}$ in the endoscopic sampling (lengths measured by ocular micrometer). In the laparoscopic biopsies, pressure artefacts due to squeeze by tweezers were observed in some areas. The myenteric neurons showed a similar type of degenerative neuropathy in both biopsies [1], in comparison to previously defined reference values [8]. Several neurons were swollen and hypertrophic ( $>40 \mu \mathrm{m}$; [16]), with or without enlarged nucleoli (Fig. 1). A few shrunken neurons with amphophilic cytoplasm and shrunken, hyperchromatic nuclei occurred (not shown). Vacuoles of various sizes were found in the cytoplasm of several neurons with or without enlarged nucleoli (Fig. 1). Neurons with chromatolysis and marginalized Nissl granules as well as a $65-\mu \mathrm{m}$ large shadow of a necrotized neuron were noted (Fig. 2). Furthermore, large PAS diastase-positive lipofuscin (Fig. 1, insert) and vimentinpositive granules were accumulated in some neurons. The immunophenotype of the neurons was pathological; several were negative for synaptophysin or showed large synaptophysinpositive granules in the Golgi region. The strongly stained pericellular positive ring (corresponding to the synaptic vesicles) was missing or irregular at the larger neurons. Several neurons were negative for Bcl-2 (a sign of preapoptosis) (Fig. 3), in contrast to a control material where all neurons were positive for Bcl-2 [4]. Several neurons had increased diffuse and granular staining for p62 (Fig. 4). In one neuron, a p62-positive (an indicator of autophagia) aggregate was present. No CD3-positive lymphocytes were noted at or within the myenteric ganglia/neural trunks. The cellular alterations of the myenteric neurons were similar in both biopsies.

The number of vacuolated myenteric neurons in the laparoscopic biopsy was 21 of 88 neurons (24\%), whereas in the endoscopic biopsy the number of vacuolated myenteric neurons was 81 of 230 neurons (35\%).

\section{Discussion}

The repeated examinations showed a similar type of cellular degeneration in the myenteric neurons in both biopsies, with an approximate $70 \%$ increase of vacuolated neurons during 1 year. The detection of a dead neuron, which is a rare finding in full-thickness biopsies, also indicates the severity of the neuronal damage.

Endoscopic full-thickness biopsy sampling was superior that obtained by the laparoscopic method in tissue quality, because the length of the myenteric plexus and the number of myenteric neurons were much greater. However, due to a single biopsy sampling for 
comparison, it is impossible to deem the endoscopic device superior to the laparoscopic device. The reason for better quality after endoscopic sampling may be that the procedure is performed without anesthesia, which may reduce peripheral oxygenation. Furthermore, the laparoscopic procedure may lead to stretching and squeezing of the intestines, which may induce mechanical pressure artefacts. Since full-thickness biopsies are difficult to obtain, the natural progress of enteric neuropathy is sparsely described in the literature. The neuropathy could theoretically be patchy and developed to different degrees in the ileum and the colon. Our previous experiments in a rat model $[17,18]$, and the findings in humans [8], did, however, show a uniform neuropathy all along the large and small bowel. Thus, the observed deterioration may rather describe disease progression than a predilection of greater damage in the large bowel. The clinical pattern in this patient also supports disease progression.

Unfortunately, a bowel rupture was observed a few days after insertion of the endoscopic device, and the patient had to undergo abdominal surgery. Bowel perforation is a known side effect of full-thickness biopsy sampling, and has been described in 3 out of 94 patients (manufacturer's information). Hypothetically, the perforation risk may be greater in patients with dysmotility compared to patients with polyps, due to disturbed pressure and peristalsis in the bowel. Previous biopsy samplings at our department did not lead to any complications [19]. An alternative endoscopic device with mainly submucosal biopsy sampling has also recently been presented, to avoid laparoscopic sampling [20].

Concomitant symptoms and signs of enteric neuropathy and autonomic neuropathy have been described previously in patients with severe dysmotility [21], which is explained by the fact that the ENS is part of the autonomic nervous system [2]. Previous research has shown a progression over time of the autonomic neuropathy related to Crohn disease [22], which is in alignment with the present findings of progressive enteric neuropathy. The expression of antibodies against GnRH or its precursor is supposed to reflect a marker of neuropathy, after leakage of neuronal GnRH [13]. However, we do not know whether the autoantibody development originates from GnRH-containing nerves in the ENS or the central nervous system $[4,6]$. The presence of the rare G allele at the SNP rs6755901 of the LHCGR gene has been described in several of the women who have developed sever dysmotility after treatment with GnRH analogs [11]. The hypothesis is that this uncommon allele may predispose to the adverse effects by GnRH on the bowel.

In conclusion, the endoscopic full-thickness device offers a sampling device with the possibility of high-quality histopathological evaluation. Enteric neuropathy may show a clinical and histopathological progression over time.

\section{Acknowledgment}

This study was supported by grants from the Development Foundation of Region Skåne.

\section{Statement of Ethics}

This study was approved by the Ethics Review Board of Lund University $(2015 / 786)$. The patient gave her written, informed consent before inclusion in the study. 


\section{Case Reports in \\ Gastroenterology}

Case Rep Gastroenterol 2018;12:32-40

DOI: $10.1159 / 000486390$

(C) 2018 The Author(s). Published by S. Karger AG, Basel www.karger.com/crg

Ohlsson et al: Endoscopic versus Laparoscopic Full-Thickness Biopsy in the Pathological Evaluation of the Enteric Nervous System

\section{Disclosure Statement}

The authors have no conflicts of interest to disclose.

\section{References}

1 Lindberg G, Tornblom H, Iwarzon M, et al: Full-thickness biopsy findings in chronic intestinal pseudoobstruction and enteric dysmotility. Gut 2009;58:1084-1090.

-2 Knowles CH, Veress B, Kapur RP, et al: Quantitation of cellular components of the enteric nervous system in the normal human gastrointestinal tract-report on behalf of the Gastro 2009 International Working Group. Neurogastroenterol Motil 2011;23:115-124.

-3 Törnblom H, Lindberg G, Nyberg B, Veress B: Full-thickness biopsy of the jejunum reveals inflammation and enteric neuropathy in irritable bowel syndrome. Gastroenterology 2002;123:1972-1979.

-4 Ohlsson B, Veress B, Janciauskiene S, et al: Chronic intestinal pseudo-obstruction due to buserelininduced formation of anti-GnRH antibodies. Gastroenterology 2007;132:45-51.

-5 Fritscher-Ravens A, Milla P, Ellrichmann M, et al: A novel endoscopic prototype device for gastric fullthickness biopsy for the histopathologic diagnosis of GI neuromuscular pathology: in vivo porcine longterm survival study (with videos). Gastrointest Endosc 2013;77:262-271.

-6 Naor Z: Signaling by G-protein-coupled receptor (GPCR): studies on the GnRH receptor. Front Neuroendocrinol 2009;30:10-29.

7 Trabant H, Widdra W, de Looze S: Efficacy and safety of intranasal buserelin acetate in the treatment of endometriosis: a review of six clinical trials and comparison with danazol. Prog Clin Biol Res 1990;323:357-382.

8 Hammar O, Ohlsson B, Veress B, et al: Depletion of enteric gonadotropin-releasing hormone is found in a few patients suffering from severe gastrointestinal dysmotility. Scand J Gastroenterol 2012;47:165173.

- Hammar O, Veress B, Montgomery A, Ohlsson B: Expression of luteinizing hormone receptor in the gastrointestinal tract in patients with and without dysmotility. Drug Target Insights 2012;6:13-18.

10 Sand E, Bergvall M, Ekblad E: Expression and distribution of GnRH, LH, and FSH and their receptors in gastrointestinal tract of man and rat. Regul Pept 2013;187:24-28.

11 Cordeddu L, Bergvall M, Sand E, et al: Severe abdominal complaints after treatment with gonadotropinreleasing hormone analogs. Scand J Gastroenterol 2015;50:291-299.

$\checkmark 12$ Hammar O, Roth B, Bengtsson M, et al: Autoantibodies and gastrointestinal symptoms in infertile women in relation to in vitro fertilization. BMC Pregnancy Childbirth 2013;13:201.

13 Roth B, Berntorp K, Ohlsson B: The expression of serum antibodies against gonadotropin-releasing hormone (GnRH1), progonadoliberin-2, luteinizing hormone (LH), and related receptors in patients with gastrointestinal dysfunction or diabetes mellitus. Drug Target Insights 2014;8:45-50.

14 Schmidt A, Meier B, Caca K: Endoscopic full-thickness resection: current status. World J Gastroenterol 2015;21:9273-9285.

15 Knowles CH, De Giorgio R, Kapur RP, et al: The London Classification of gastrointestinal neuromuscular pathology: report on behalf of the Gastro 2009 International Working Group. Gut 2010;59:882-887.

-16 Smith VV: Intestinal neuronal density in childhood: a baseline for the objective assessment of hypo- and hyperganglionosis. Pediatr Pathol 1993;13:225-237.

-17 Sand E, Voss U, Hammar O, et al: Gonadotropin-releasing hormone analog buserelin causes neuronal loss in rat gastrointestinal tract. Cell Tissue Res 2013;351:521-534.

18 Sand E, Roth B, Weström B, et al: Structural and functional consequences of buserelin-induced enteric neuropathy in rat. BMC Gastroenterol 2014;14:209.

19 Ohlsson B, Gustafsson R, Swahn F, et al: Endoscopic full-thickness biopsy, a novel method in the workup of complicated abdominal symptoms. Therap Adv Gastroenterol 2018;11:1-4.

-20 Rajan E, Gostout CJ, Wong Kee Song LM, et al: Innovative gastric endoscopic muscle biopsy to identify all cell types, including myenteric neurons and interstitial cells of Cajal in patients with idiopathic gastroparesis: a feasibility study (with video). Gastrointest Endosc 2016;84:512-517.

21 Mattsson T, Roos R, Sundkvist G, et al: Sympathetic nerve dysfunction is common in patients with chronic intestinal pseudo-obstruction. J Clin Gastroenterol 2008;42:174-177.

22 Ohlsson B, Sundkvist G, Lindgren S: Subclinical sympathetic neuropathy appears early in the course of Crohn's disease. BMC Gastroenterol 2007;7:33. 


\begin{tabular}{|c|c|c|}
\hline \multirow{2}{*}{$\begin{array}{l}\text { Case Reports in } \\
\text { Gastroenterology }\end{array}$} & \multicolumn{2}{|c|}{ Case Rep Gastroenterol 2018;12:32-40 } \\
\hline & DOI: $10.1159 / 000486390$ & $\begin{array}{l}\text { O } 2018 \text { The Author(s). Published by S. Karger AG, Basel } \\
\text { www.karger.com/crg }\end{array}$ \\
\hline
\end{tabular}

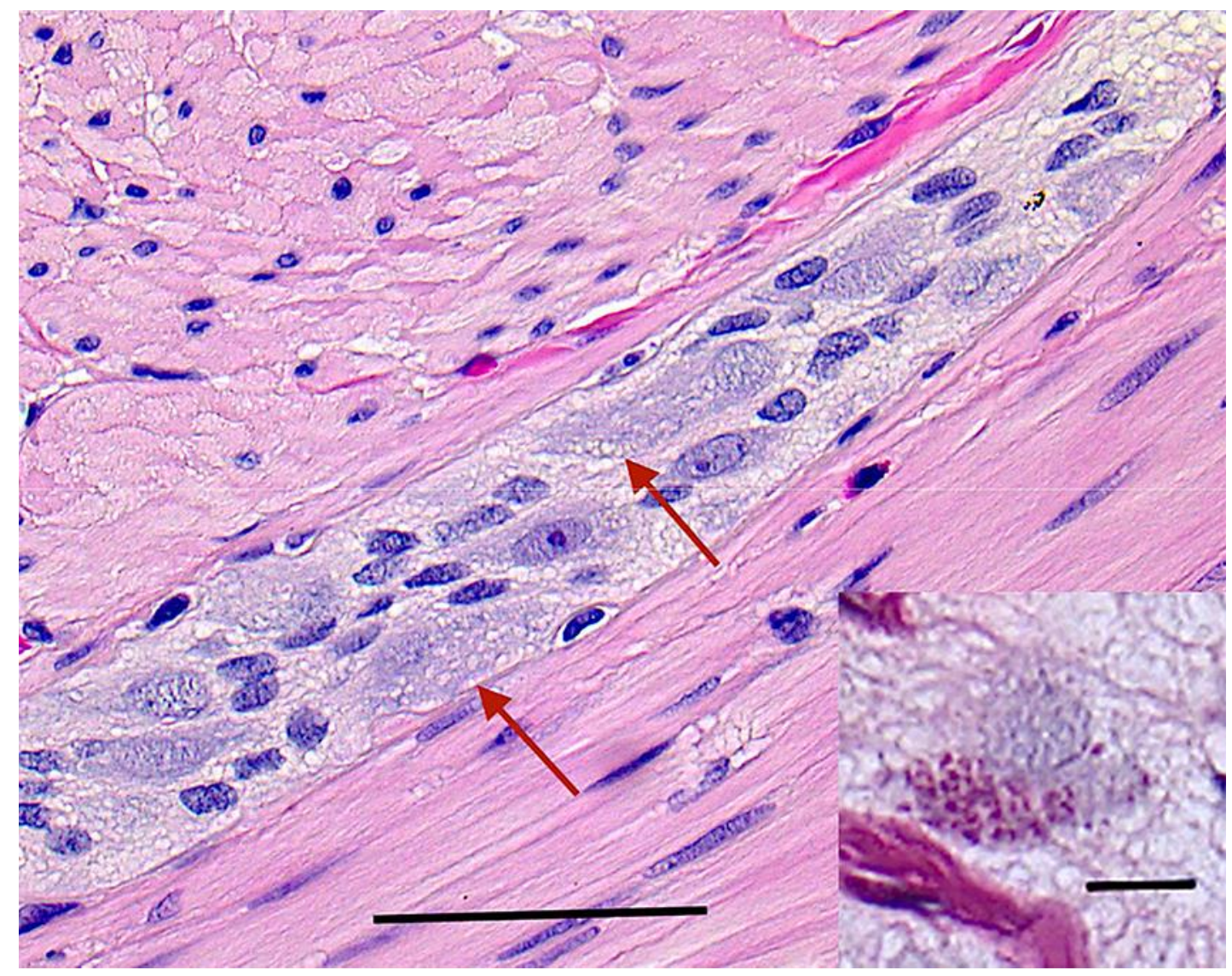

Fig. 1. Myenteric ganglion from the endoscopic sample showing several vacuolated neurons (arrows) and an enlarged nucleolus in one of these cells. H\&E. Scale bar, $50 \mu \mathrm{m}$. Insert Large accumulation of lipofuscin granules in a myenteric neuron. PAS diastase. Scale bar, $10 \mu \mathrm{m}$. 


\section{Case Reports in
Gastroenterology

\begin{tabular}{l|l}
\hline Case Rep Gastroenterol 2018;12:32-40 \\
\hline DOI: 10.1159/000486390 & $\begin{array}{l}\text { c } 2018 \text { The Author(s). Published by S. Karger AG, Basel } \\
\text { www.karger.com/crg }\end{array}$ \\
\hline
\end{tabular} \\ Ohlsson et al.: Endoscopic versus Laparoscopic Full-Thickness Biopsy in the Pathological}

Evaluation of the Enteric Nervous System

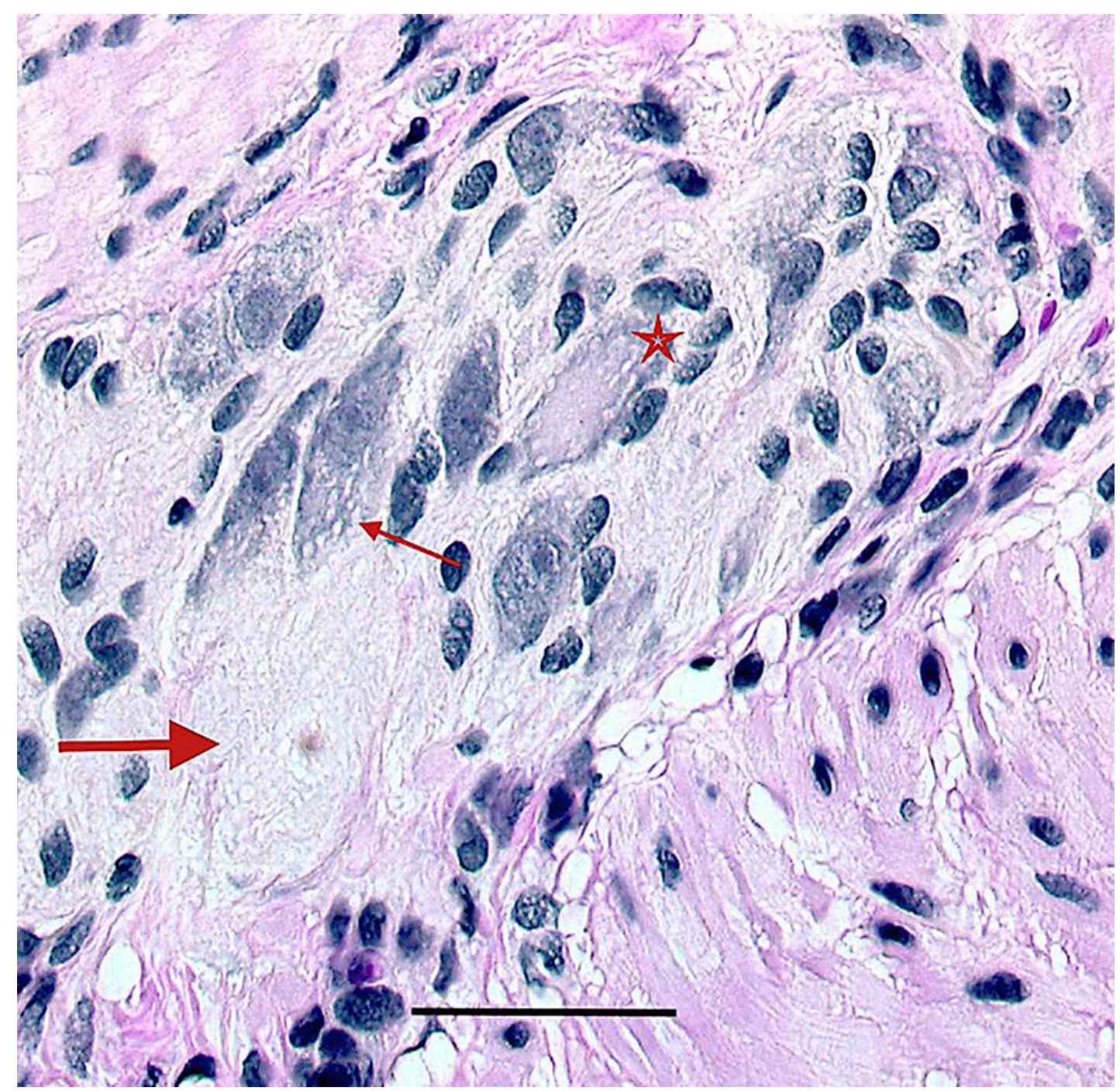

Fig. 2. Myenteric ganglion from the laparoscopic sample with vacuolated neurons (thin arrow), one of which shows chromatolysis, marginalization of the Nissl granules, and small vacuoles at the periphery of the cytoplasm (star). The large arrow points to the $65-\mu \mathrm{m}$ shadow of a necrotized neuron with the remnant of the nucleolus. H\&E. Scale bar, $50 \mu \mathrm{m}$. 


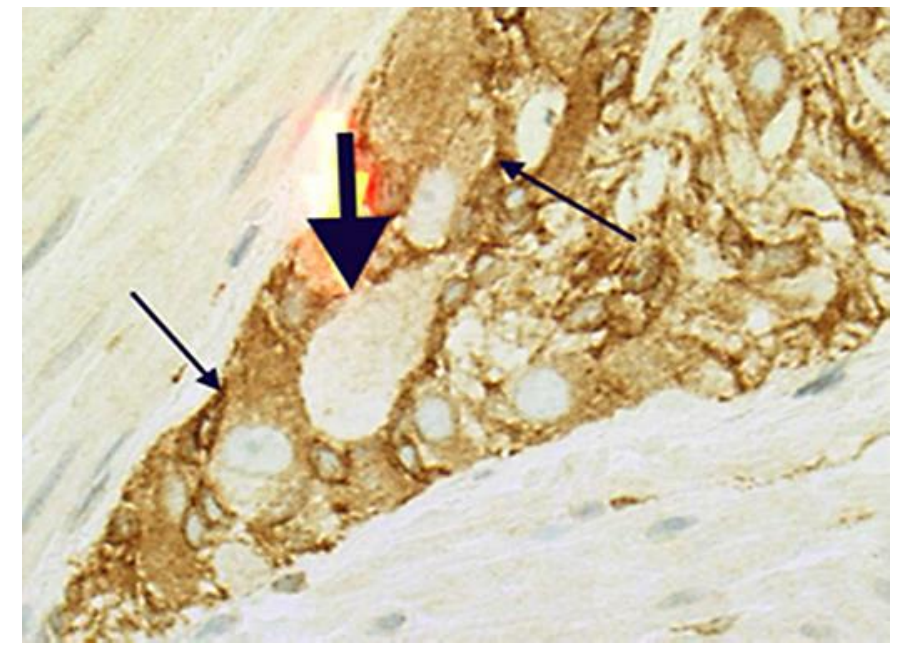

Fig. 3. One large neuron is negative for Bcl-2 in immunohistochemical staining (thick arrow) between 2 positive neurons (thin arrows). Magnification, $\times 240$.

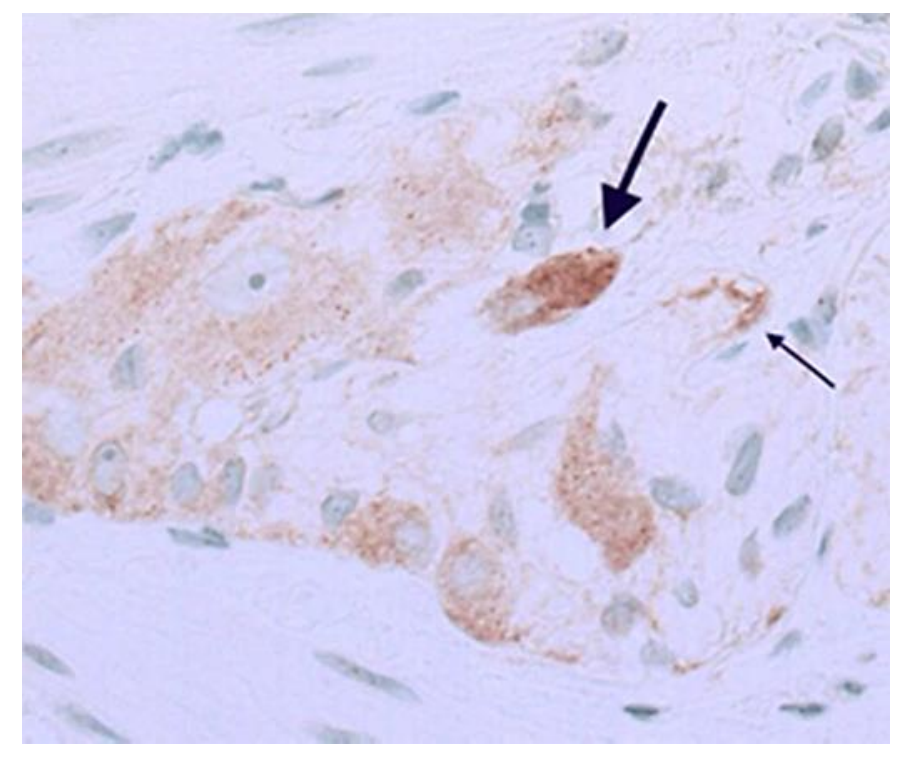

Fig. 4. One neuron shows strongly increased immunoreactivity for p62 with several coarse granules (thick arrow). Another smaller neuron shows vacuoles and increased positivity (thin arrow). The reaction is normal in the other neurons. Magnification, $\times 240$. 